\title{
Urban women's socioeconomic status, health service needs and utilization in the four weeks after postpartum hospital discharge: findings of a Canadian cross-sectional survey Christine Kurtz Landy*, Wendy Sword and Donna Ciliska
}

\author{
Address: School of Nursing, McMaster University, 1200 Main Street W., Hamilton, Ontario, L8N 3Z5, Canada \\ Email: Christine Kurtz Landy* - kurtzlcm@mcmaster.ca; Wendy Sword - sword@mcmaster.ca; Donna Ciliska - ciliska@mcmaster.ca \\ * Corresponding author
}

Published: 3 October 2008

BMC Health Services Research 2008, 8:203 doi:10.1 186/1472-6963-8-203

This article is available from: http://www.biomedcentral.com/l472-6963/8/203

(c) 2008 Kurtz Landy et al; licensee BioMed Central Ltd.

This is an Open Access article distributed under the terms of the Creative Commons Attribution License (http://creativecommons.org/licenses/by/2.0), which permits unrestricted use, distribution, and reproduction in any medium, provided the original work is properly cited.

\begin{abstract}
Background: Postpartum women who experience socioeconomic disadvantage are at higher risk for poor health outcomes than more advantaged postpartum women, and may benefit from access to community based postpartum health services. This study examined socioeconomically disadvantaged (SED) postpartum women's health, and health service needs and utilization patterns in the first four weeks post hospital discharge, and compared them to more socioeconomically advantaged (SEA) postpartum women's health, health service needs and utilization patterns.
\end{abstract}

Methods: Data collected as part of a large Ontario cross-sectional mother-infant survey were analyzed. Women $(\mathrm{N}=1000)$ who had uncomplicated vaginal births of single 'at-term' infants at four hospitals in two large southern Ontario, Canada cities were stratified into SED and SEA groups based on income, social support and a universally administered hospital postpartum risk screen. Participants completed a self-administered questionnaire before hospital discharge and a telephone interview four weeks after discharge. Main outcome measures were self-reported health status, symptoms of postpartum depression, postpartum service needs and health service use.

Results: When compared to the SEA women, the SED women were more likely to be discharged from hospital within the first 24 hours after giving birth [OR I.49, 95\% Cl (I.0I-2.I8)], less likely to report very good or excellent health [OR $0.48,95 \% \mathrm{Cl}(0.35-0.67)]$, and had higher rates of symptoms of postpartum depression [OR $2.7,95 \% \mathrm{Cl}(\mathrm{I} .64-4.4)]$. No differences were found between groups in relation to self reported need for and ability to access services for physical and mental health needs, or in use of physicians, walk-in clinics and emergency departments. The SED group were more likely to accept public health nurse home visits [OR 2.24, 95\% $\mathrm{Cl}(\mathrm{I} .47-3.40)$ ].

Conclusion: Although SED women experienced poorer mental and overall health they reported similar health service needs and utilization patterns to more SEA women. The results can assist policy makers, health service planners and providers to develop and implement necessary and accessible services. Further research is needed to evaluate SED postpartum women's health service needs and barriers to service use. 


\section{Background}

Although socioeconomically disadvantaged (SED) populations can benefit from the use of health and social services [1], there is a paucity of published research regarding SED women's health and social service needs and utilization patterns during the postpartum period. Women who are socioeconomically disadvantaged often experience inequities in health and health care. In their daily lives they face chronic stressors such as poverty, lack of social support, isolation, racism, violence, language barriers, and low levels of education [2,3]. These challenges create a complex burden of psychosocial, functional, and physical health risks which can obstruct their access to material resources and health care, and in turn put them at high risk for poor health outcomes and poor quality of life [2$4]$. During the postpartum period SED women experience higher rates of postpartum depression, with reported rates between $22 \%$ and $30 \%$ [5-8] compared to $13 \%$ overall prevalence in the general population $[9,10]$. They are more likely to suffer from iron deficiency than their more SEA counterparts [11]. In addition SED postpartum women have more problems adjusting to the parenting role [12], report higher rates of intimate partner violence $[13,14]$, are less likely to breastfeed $[15]$ and are less likely to have a partner [16].

Studies report that SED postpartum women may have shorter hospital stays and may not be getting appropriate follow-up in the community [17]. In the prenatal period, American and Canadian studies show that SED women do not use recommended levels of health care even when financial barriers are lifted [18-21]. This pattern of health service utilization may carry over into the postpartum period, and may be reinforced by the problem that postpartum health care is often neglected, especially as it pertains to women's health [22-24]. Yet postpartum care integrated into a prenatal-postnatal care continuum is likely just as important in promoting short and long-term health as prenatal care, particularly for SED women and, in turn, for their children $[22,24,25]$.

In Ontario, Canada, $98 \%$ of women give birth in hospital [26]. Hospitalization and visits to health care providers (physicians, midwives and nurses practitioners) and home visits by public health nurses are paid for by public health insurance and government programs with no additional out of pocket costs to patients in accordance with the Canada Health Act $[27,28]$. Over the last two decades length of postpartum hospital stay has shortened to an average of two days for women who have vaginal births [29]. Women access most of their postpartum care in the community. In the late 1990s the Ontario government responded to health professionals' concerns about the safety of the shortened length of postpartum hospital stay and the lack of standardized community based postpar- tum care by introducing the Healthy Babies Healthy Children Postpartum Enhancement [28]. Under this program all women are to be offered a 60 hour postpartum hospital stay, a public health nurse telephone call within 48 hours after hospital discharge to assess postpartum adjustment and family's level of risk for poor health outcomes, and an offer of a public health nurse home visit in which postpartum adjustment, infant and maternal health, and family functioning would be assessed and families would be referred to appropriate community services [28]. Inherent in the program is the assumption that those most in need will use the services offered and that there is appropriate and responsive services available for all postpartum women and their infants. However there is a dearth of information about which health and social services SED postpartum women in fact need and use to help them through the often challenging physical, emotional, and social changes that characterize the postpartum period.

This manuscript presents the findings of Phase 1 of a mixed methods study (undertaken from 2003 to 2005) examining health and social service needs and utilization patterns of SED postpartum women in the first four weeks after hospital discharge. The purpose of this phase of the study is to describe SED women's postpartum health at four weeks following hospital discharge and to compare it to more socioeconomically advantaged (SEA) postpartum women. In addition the SED women's postpartum health service needs and utilization of needed services will be described and compared to those of more SEA women.

\section{Methods}

Data collected from postpartum women recruited at the four large urban hospital sites of The Ontario Mother Infant Survey II, a multi-site cross-sectional survey, in Ontario, Canada are presented in this paper. The Ontario Mother Infant Survey II was conducted to evaluate health outcomes, and health and social service needs and utilization patterns, and costs of care for postpartum women and their newborns in the first four weeks following hospital discharge. The focus of this larger study was not on socioeconomically disadvantaged postpartum women. However the research produced some important findings about this group that have not been reported in the literature. Ethical approval was received from the four hospital sites and McMaster University's research ethics board.

Trained research assistants on the postpartum units at the four hospital sites approached eligible postpartum women and explained the study. Women were eligible if they gave vaginal birth to full term singleton infants, were discharged together with their infant, were able to communicate in one of the five study languages (English, French, Spanish, Mandarin and Cantonese) and had a telephone. The first 250 postpartum women who were eligi- 
ble and gave informed consent at each site were recruited into the study. In total 1000 women were recruited at the four sites.

Participants completed a self-administered questionnaire collecting their sociodemographic information before postpartum hospital discharge. In addition, for the purpose of this study, the research assistants collected the participants' Parkyn Postpartum Screen scores from their hospital charts. The Parkyn Postpartum Screen is a multidimensional tool assessing family socioeconomic and health risk, universally administered in Ontario postpartum hospital units to screen for families at high risk for poor health outcomes [30]. A score of 9 or above is indicative of high risk for poor health outcomes. Four weeks after hospital discharge participants undertook a structured telephone interview administered by trained interviewers. The interview included questions about hospital length of stay, maternal and infant health, social support, needs for care, ability to access care, and health and social services utilization. The Duke-UNC Functional Social Support Questionnaire [31], the Edinburgh Postnatal Depression Scale (EPDS) [32], and a modified Health and Social Service Utilization Questionnaire [33] were used in the telephone interviews to examine social support, risk of postpartum depression, and participants' recall of service use respectively. The Duke-UNC Functional Social Support Questionnaire contains two subscales measuring affective and confidant support. The subscales are reliable with reported alpha coefficients for confidant support = 0.62 and for affective support $=0.76$ [31]. The EPDS is a valid measure of risk for postpartum depression with the following psychometric properties: sensitivity $86 \%$, specificity $78 \%$, positive predictive value $73 \%$, split-half reliability 0.88 , and alpha coefficient 0.87 [32]. Women scoring 12 or above on the EPDS were considered at high risk for postpartum depression. The Health and Social Service Utilization Questionnaire has adequate levels of agreement with clinic records (between 0.72 and 0.99 and Kappa ranges from 0.48 to 0.89 ) [34].

The 1000 participants were stratified into SED and more SEA groups. Participants fell into the SED group if they met any one or more of the following criteria: (a) a Parkyn Postpartum Screen score of 9 or above [30], (b) gross family income less than $\$ 20,000$ per year, or (c) low social support, defined as a score below the $15^{\text {th }}$ percentile on the Duke-UNC Functional Social Support Questionnaire [31]. Participants whose socioeconomic status could not be determined because of missing data on the criteria listed above were excluded from the analysis.

SPSS 12.00 was used to enter and analyze the data. Descriptive statistics were used to profile the characteristics of the participants, health services needed and services used. Inferential statistics were used to compare proportions and means between the SED and more SEA groups. For categorical data $2 \times 2$ tables the Fisher's Exact test was used; for data with more than two categories the chi square statistic was used. The $95 \%$ confidence intervals (CI) of the proportions were computed using approximation of the normal distribution. To compare the groups with regard to continuous variables, the independent ttest was used and 95\% confidence intervals around the means were calculated. The $\mathrm{p}$ value was set at .05 . Odds ratios (OR) together with $95 \%$ confidence intervals were calculated to further evaluate differences between the SED and more SEA groups.

\section{Results}

Of the 1000 women who entered the study at the four sites, socioeconomic status could only be determined for 726 participants due to missing data regarding family income and/or social support and/or Parkyn Postpartum Screen Scores; 295 women fell into the SED group and 431 women fell into the SEA group. The telephone interview undertaken four weeks after hospital discharge was completed by 217 of the SED women and 431 of the SEA women. The women stratified into the SED group who did not complete the telephone interview $(\mathrm{n}=78)$ were compared to the SED women who completed the telephone interview $(\mathrm{n}=217)$. The SED women who did not complete the telephone interview were younger $(M=26.6$ years compared to 28.5 years, $p<.01$ ) and less likely to have a partner $(64 \%$ compared to $79 \%, p<.025)$. No differences were found between the SED women who completed the telephone interview and those who did not with regard to education, language spoken at home, country of birth, baby's birth weight and having a family doctor.

For the participants who completed the study the mean age of women in the SED $(n=217)$ and more SEA groups $(n=431)$ were 28.5 years (range 16 to 43 ) and 30.4 years (range 19 to 42 ) respectively $(\mathrm{p}<.001)$. Forty percent of the women in the SED group and $47 \%$ of the women in the SEA group had just given birth to their first child [OR $0.75,95 \%$ CI $(0.54-1.04)]$.

Various attributes of the women in the SED and SEA groups are shown in Table 1. The women in the SED group were significantly less likely to have a partner, to speak English at home, to identify their ethnicity as Canadian, to have a high school diploma and were significantly more likely to have been born outside of Canada. For the women born abroad, length of time in Canada was found to be significantly associated with socioeconomic status. SED women born abroad had lived in Canada for fewer years than SEA women born abroad $[M=7.5$ 
Table I: Profile of SED and SEA postpartum women by selected attributes

\begin{tabular}{|c|c|c|c|c|c|}
\hline \multirow{2}{*}{ Attributes } & \multicolumn{2}{|c|}{ SED Group } & \multicolumn{2}{|c|}{ SEA Group } & \multirow{2}{*}{$\begin{array}{l}\text { Unadjusted } \\
\text { OR (95\% Cl) }\end{array}$} \\
\hline & $N^{a}$ & $\%$ & $N^{a}$ & $\%$ & \\
\hline \multicolumn{6}{|l|}{ SOCIODEMOGRAPHIC } \\
\hline Marital Status & 213 & & 424 & & \\
\hline Has partner & & 79 & & 99 & $0.05(0.02-0.13)$ \\
\hline Education & 212 & & 432 & & \\
\hline Less than high school & & 25 & & 5 & $2.25(1.93-2.63)$ \\
\hline Cultural Identity & 211 & & 428 & & \\
\hline Canadian & & 50 & & 61 & $0.61(0.44-0.85)$ \\
\hline Language Spoken at Home & 217 & & 431 & & \\
\hline English & & 63 & & 82 & $0.37(0.26-0.49)$ \\
\hline Country of Birth & 215 & & 421 & & \\
\hline Canada & & 45 & & 70 & $0.35(0.25-0.49)$ \\
\hline \multicolumn{6}{|l|}{ WOMAN'S HEALTH } \\
\hline Overall Health & 215 & & 431 & & \\
\hline Very good/Excellent & & 41 & & 59 & $0.48(0.35-0.67)$ \\
\hline Symptoms of Postpartum Depression & 211 & & 426 & & \\
\hline EPDS $\geq 12$ & & 19 & & 8 & $2.7(1.64-4.4)$ \\
\hline Hospital Readmission & 216 & & 431 & & \\
\hline YES & & 3 & & 2 & $1.57(0.57-4.28)$ \\
\hline \multicolumn{6}{|l|}{ PHYSICIAN } \\
\hline Has Family Doctor & 215 & & 430 & & \\
\hline YES & & 96 & & 97 & $0.74(0.3-1.84)$ \\
\hline
\end{tabular}

Note: a Sample sizes for some variables differ from study $\mathrm{N}$ because of missing data. *Number who initiated breastfeeding. SED = socioeconomically disadvantaged, $\mathrm{SEA}=$ more socioeconomically advantaged. EPDS = Edinburgh Postpartum Depression Scale

years, $S D=6.87 ; 95 \% \mathrm{CI}(6.21-8.7)$ and $M=12.1$ years, $S D=9.2 ; 95 \%$ CI $(10.7-13.4)$ respectively, $p<.001]$.

At four weeks post discharge SED women were significantly less likely to rate their health as very good or excellent and had 2.7 times higher odds of experiencing symptoms of postpartum depression than the SEA women. Over $95 \%$ of women in both groups had family doctors. There was no significant difference between the SED and SEA groups' reported offer of the government mandated 60 hour postpartum hospital stay (48\% versus $53 \%$ respectively). A higher proportion of women in the

Table 2: Postpartum women's need for and receipt of help and/or care in the first 4 weeks

\begin{tabular}{|c|c|c|c|c|c|c|c|}
\hline \multirow[t]{2}{*}{ Variables } & \multicolumn{3}{|c|}{ SED Group } & \multicolumn{3}{|c|}{ SEA Group } & \multirow{2}{*}{$\begin{array}{l}\text { Unadjusted } \\
\text { OR }(95 \% \mathrm{Cl})\end{array}$} \\
\hline & $N$ & $\%$ & $n$ & $N$ & $\%$ & $n$ & \\
\hline \multicolumn{8}{|c|}{ Care for a physical health problem } \\
\hline Needed & 217 & 19 & 41 & 431 & 25 & 108 & $0.70(0.47-1.1)$ \\
\hline Received & $4 I^{*}$ & 90 & 37 & $108^{*}$ & 94 & 102 & $0.54(0.15-2.0)$ \\
\hline \multicolumn{8}{|c|}{ Care for an emotional/mental health problem } \\
\hline Needed & 217 & 8 & 17 & 431 & 5 & 21 & $1.78(0.93-3.4 I)$ \\
\hline Received & $17 *$ & 67 & 12 & $21 *$ & 71 & 15 & $0.80(0.21-3.13)$ \\
\hline \multicolumn{8}{|c|}{ Help with breast feeding ${ }^{a}$} \\
\hline Needed & 187 & 37 & 69 & 402 & 44 & 172 & $0.78(0.54-1.10)$ \\
\hline Received & $69 *$ & 91 & 63 & $172 *$ & 93 & 160 & $0.80(0.29-2.20)$ \\
\hline \multicolumn{8}{|c|}{ Household help } \\
\hline Needed & 217 & 26 & 56 & 431 & 26 & 112 & $0.97(0.67-1.40)$ \\
\hline Received & $56^{*}$ & 77 & 42 & $112 *$ & 90 & 101 & $0.43(0.17-1.10)$ \\
\hline \multicolumn{8}{|c|}{ Reassurance/support } \\
\hline Needed & 217 & 25 & 54 & 431 & 27 & 115 & $0.89(0.61-1.30)$ \\
\hline Received & $54^{*}$ & 85 & 44 & $115^{*}$ & 98 & 113 & $0.11(0.02-0.48)$ \\
\hline \multicolumn{8}{|c|}{ Financial Support } \\
\hline Needed & 217 & 18 & 38 & 431 & 3 & 10 & $7.08(3.69-13.6)$ \\
\hline Received & $36 *$ & 64 & 24 & $10 *$ & 60 & 6 & $1.05(0.33-3.25)$ \\
\hline
\end{tabular}

Note: a Only women who initiated breastfeeding are included.* Number reported needing the service. SED = socioeconomically disadvantaged, SEA $=$ more socioeconomically advantaged 
SED group (27\%) reported being discharged from hospital within 24 hours after giving birth compared to the SEA group (20\%) [OR 1.49, 95\% CI (1.01-2.18)]. For those women who were discharged within 24 hours, there was no difference between the SED and SEA groups with regard to whether this was their first live birth $30 \%$ compared to $31 \%$ respectively, $p<1.0$ ). A lower proportion of the SED group (88\%) initiated breastfeeding compared to the SEA group (93\%) [OR 0.53, 95\% CI (0.03-0.91)]. However, at four weeks post discharge $83 \%$ of SED women and $81 \%$ of SEA women who had initiated breastfeeding were still breastfeeding [OR 0.99, 95\% CI (0.651.53)]. Hospital readmission rates were low for both groups.

As shown in Table 2, there were no statistically significant differences between SED and SEA groups with regard to need for care for physical health problems, emotional/ mental health problems, household help, reassurance/ support or help with breastfeeding. Not surprisingly significantly more of the SED women needed financial aid than SEA women. A high proportion of women in SED and SEA groups reported getting help for physical health problems and breastfeeding. Although not statistically significant, a smaller proportion of the women in the SED group reported receipt of help for emotional/mental health problems. Nonetheless, approximately one third of women in both groups went without needed help for this type of problem. Similarly, only $64 \%$ of the SED group and $60 \%$ of the more SEA group who needed financial assistance received this assistance. A significantly smaller proportion of the SED women who reported needing reassurance and support were able to obtain this type of help.

No statistically significant differences in use of physician and midwifery services were found between groups (Table 3 ). Family doctors were the most frequently accessed primary health care providers. Women in both groups made up to four visits, with $75 \%$ of the SED group and $73 \%$ of the SEA group having made only one visit. Obstetriciangynaecologists were the second most reported physician service used by both groups. Few women reported using emergency rooms and walk-in clinics.

Over $80 \%$ of women in both groups reported having received a telephone call from a public health nurse (Table 4). However the SED group was significantly less likely to receive the phone call within the government mandated 48 hours after hospital discharge. A high proportion of women in both groups were offered a home visit. The odds of accepting the offer of a public health nurse home visit were more than two times higher in the SED group. In addition the SED group's odds for continued involvement with public health were 2.5 times higher at four weeks post hospital discharge than the SEA group. The SED group received significantly more public health nurse home visits $(p<.001)$.

Table 5 compares the proportion of women in the SED and SEA groups who used other community based health and social services. Breastfeeding clinics were the service most often used by both groups. The SED group was significantly more likely to use food banks, social assistance, and the Children's Aid Society. Few women in both groups reported using services such as postpartum support groups, parenting classes, and family resource centres in the first four weeks at home.

\section{Discussion}

This is one of the first studies to examine SED postpartum women's health and social service needs and use. Although this study did not use a random sample of women who had medically uneventful vaginal deliveries of healthy infants it provides a snapshot of SED women delivering in large Canadian urban centres and of their health and social service needs and use in the early postpartum weeks.

Table 3: Postpartum women's utilization of physician and midwifery services

\begin{tabular}{|c|c|c|c|c|c|}
\hline \multirow[t]{2}{*}{ Physician and Midwifery Services } & \multicolumn{2}{|c|}{ SED Group $(N=217)$} & \multicolumn{2}{|c|}{ SEA Group $(N=431)$} & \multirow{2}{*}{$\begin{array}{l}\text { Unadjusted } \\
\text { OR }(95 \% \mathrm{Cl})\end{array}$} \\
\hline & $\%$ & $n$ & $\%$ & $n$ & \\
\hline Visit to family physician & 30 & 65 & 28 & 121 & $1.06(0.84-1.34)$ \\
\hline Phone call to family physician & 9 & 20 & 8 & 35 & $1.09(0.76-1.58)$ \\
\hline Visit to midwife & 2 & 4 & 4 & 17 & $0.64(0.95-1.48)$ \\
\hline Visit from midwife & 4 & 9 & 7 & 30 & $0.72(0.40-1.28)$ \\
\hline Phone call to midwife & 1 & 2 & 2 & 9 & $0.74(0.28-1.99)$ \\
\hline Visit to an OBGYN & 12 & 26 & 8 & 35 & $1.33(0.98-1.82)$ \\
\hline Phone call to OBGYN & 7 & 15 & 6 & 26 & $1.04(0.69-1.57)$ \\
\hline Visit to another specialist & 2 & 4 & 3 & 13 & $0.93(0.46-1.94)$ \\
\hline Emergency room visit & 5 & 11 & 4 & 17 & $1.10(0.68-1.78)$ \\
\hline Walk-in clinic visit & 2 & 4 & 4 & 17 & $0.70(0.33-1.53)$ \\
\hline
\end{tabular}

Note: SED = socioeconomically disadvantaged, SEA = more socioeconomically advantaged 
Table 4: Use of public health nursing (PHN) services in the first 4 weeks after leaving hospital

\begin{tabular}{|c|c|c|c|c|c|c|c|}
\hline \multirow[t]{2}{*}{ Type of contact } & \multicolumn{3}{|c|}{ SED Group } & \multicolumn{3}{|c|}{ SEA Group } & \multirow{2}{*}{$\begin{array}{l}\text { Unadjusted } \\
\text { OR }(95 \% \mathrm{Cl})\end{array}$} \\
\hline & $N$ & $\%$ & $n$ & $N$ & $\%$ & $n$ & \\
\hline Received a PHN phone call & 217 & & & 431 & & & \\
\hline Yes & & 81 & 176 & & 86 & 371 & $0.69(0.45-1.07)$ \\
\hline PHN phone call within 48 hours after discharge? & $158^{\mathrm{a}}$ & & & $\left.37\right|^{\mathrm{a}}$ & & & \\
\hline Yes & & 87 & 137 & & 98 & 366 & $0.31(0.13-0.77)$ \\
\hline PHN home visit offered in phone call & $176^{\mathrm{a}}$ & & & $366^{\mathrm{a}}$ & & & \\
\hline Yes & & 95 & 167 & & 94 & 347 & $1.12(0.53-2.63)$ \\
\hline PHN home visit accepted & $167^{*}$ & & & $347^{*}$ & & & \\
\hline Yes & & 77 & 128 & & 60 & 208 & $2.24(1.47-3.40)$ \\
\hline Continued PHN services at 4 weeks post discharge & $124 *$ & & & $206 *$ & & & \\
\hline \multirow[t]{3}{*}{ Yes } & & 34 & 42 & & 17 & 35 & $2.5(1.49-4.21)$ \\
\hline & \multicolumn{3}{|c|}{ SED Group } & \multicolumn{3}{|c|}{ SEA Group } & \\
\hline & $N$ & $M$ & SD $95 \% \mathrm{Cl}$ & $N$ & M & SD $95 \% \mathrm{Cl}$ & $P$ \\
\hline Age in days of baby at the first PHN home visit? & $124 *$ & 6.9 & $5.5(5.8-7.7)$ & $206 *$ & 7.7 & $6.2(7.0-10.1)$ & $P<0.23$ \\
\hline Number of PHN home visits & $123 *$ & 1.9 & $1.5(1.6-2.2)$ & $207^{*}$ & 1.4 & $0.76(1.2-1.5)$ & $p<0.001$ \\
\hline
\end{tabular}

Note: a Number that received a PHN phone call who answered the question.

*Number offered a PHN home visit who answered the question. SED = socioeconomically disadvantaged, SEA = more socioeconomically advantaged

Many of the attributes of SED women in this study were similar to those found in previous research including that they were more likely to be single, younger, less educated and in poorer overall health $[16,35]$. However, distinct from previous research findings [15], a high proportion of SED women continued to breastfeed four weeks post hospital discharge.

The high representation of women born abroad (55\%) in the SED group is a concern. Researchers have found that immigrant postpartum women are more likely to get suboptimal care in hospital and in the community [36] and use health services less frequently than non immigrant women [37], particularly preventive health services [38]. The immigrant women in the SED group had lived in Canada a shorter period of time than those in the more SEA group. The findings may reflect the fact that new immigrants are often socially isolated due to separation from family and other social support networks [39] and have not had enough time to establish new social support

Table 5: Health and social services use by SED and SEA groups

\begin{tabular}{|c|c|c|c|c|c|}
\hline \multirow{2}{*}{ Health Provider or Social Services } & \multicolumn{2}{|c|}{ SED Group $(N=217)$} & \multicolumn{2}{|c|}{ SEA Group $(N=43 I)$} & \multirow{2}{*}{$\begin{array}{l}\text { Unadjusted } \\
\text { OR }(95 \% \mathrm{Cl})\end{array}$} \\
\hline & $\%$ & $n$ & $\%$ & $n$ & \\
\hline \multicolumn{6}{|l|}{ Health Providers } \\
\hline Hospital/clinic nurse & 8 & 17 & 7 & 30 & $1.09(0.73-1.62)$ \\
\hline Lay home visitor & 3 & 6 & 1 & 4 & $2.03(1.26-3.26)$ \\
\hline Telephone nurse & 7 & 15 & 12 & 52 & $0.67(0.42-1.05)$ \\
\hline Other care provider & 7 & 15 & 8 & 34 & $0.98(0.64-1.49)$ \\
\hline \multicolumn{6}{|l|}{ Services } \\
\hline Parenting class & 3 & 6 & 3 & 13 & $0.98(0.51-1.93)$ \\
\hline Postpartum support group & I & 2 & 1 & 4 & $1.29(0.54-3.05)$ \\
\hline Family resource centre & 4 & 8 & 2 & 9 & $1.52(0.94-2.44)$ \\
\hline Parenting/child drop-in & 7 & 15 & 3 & 13 & $1.53(1.06-2.25)$ \\
\hline Children's Aid Society & 4 & 8 & 0 & 0 & $3.08(2.75-3.43)$ \\
\hline Canadian Prenatal Nutrition Program & i & 2 & 0.2 & 1 & $2.26(1.27-4.03)$ \\
\hline Food bank & 5 & 11 & 0 & 0 & $3.07(2.75-3.44)$ \\
\hline Women's shelter & 0.5 & 2 & 0.2 & 1 & $1.48(0.37-6.01)$ \\
\hline Breastfeeding clinic & 13 & 28 & 18 & 77 & $0.76(0.54-1.06)$ \\
\hline Social assistance & 9 & 19 & 0.5 & 2 & $2.87(2.40-3.44)$ \\
\hline Other services & 5 & II & 5 & 22 & $1.03(0.63-1.68)$ \\
\hline
\end{tabular}

SED = socioeconomically disadvantaged, SEA = more socioeconomically advantaged 
networks. Financial hardship experienced by many new immigrants may also explain the high percentage of immigrant women in the SED group, as many new immigrants experience underemployment or unemployment [40] which likely worsens with maternity leave.

Only half of the SED women in this study reported being offered the currently mandated 60 -hour postpartum hospital stay [28], indicating that the policy is not being universally implemented. One in four of the SED women were discharged from hospital within 24 hours after giving birth, in contrast to one in five of the more SEA women. Service use findings in this study indicate that these SED women were not receiving added supportive services following discharge as recommended by Canadian obstetric and pediatric guidelines on early discharge [41]. Some SED women might have opted to leave hospital early due to negative experiences with care, as negative attitudes, lack of respect, dissatisfaction with treatment, and impersonal care have been reported as barriers to health service utilization [21].

Surprisingly few differences were found between the SED and SEA groups with regard to self-reported health service needs and use. The women in the SED group may have been too busy with the multiple challenges of their daily lives, related to socioeconomic disadvantage and a new baby, to focus on their own health needs. Given the SED group's health service utilization patterns, family doctors and public health nurses may be best positioned to screen for mental and physical health problems and offer appropriate referrals and interventions.

The SED women's inability to get needed support and reassurance is a concern. Provision of support and reassurance outside of the realm of personal social support potentially comes from community services and programs such as postpartum support groups, public health nurse home visiting, and lay home visitors. Both groups reported very low use of these types of services. As almost all the women in the SEA group reported that they received help in this domain, they likely obtained this support and reassurance from informal sources such as family and friends. More research is necessary to understand the nature of support that is needed by SED postpartum women and to develop effective strategies to deliver such support.

A large proportion of women in the SED group took advantage of Ontario's public health postpartum home visiting program. The SED women reported more public health visits than the SEA women; however the difference of a half visit (mean difference of 0.522) more in the first four weeks at home is likely not clinically significant. In addition it is not known how much of this service was ori- ented toward promotion of the women's health. The program's focus is primarily on promoting the health of atrisk children [28]; promoting mother's health is secondary and important to the degree that it affects the health of her child. Yet, the high acceptance of a home visit by SED postpartum women may indicate that they want or need the services of a public health nurse in the early postpartum weeks. The high acceptance rates may also reflect the ability of public health nurses to encourage a visit during the phone call, especially to the SED group. There should be some concern about the $19 \%$ of SED women who did not receive a public health nurse phone call. The initial postpartum telephone call is a primary point of entry into Ontario's public health postpartum follow-up program.

The low use of community services such as parenting classes and postpartum support groups may signify a lack of interest in these types of programs in the early postpartum weeks. However the low use of these programs may also indicate the existence of barriers to accessing these types of resources, such as lack of transportation and knowledge about the services.

The generalizability of these study findings is limited by the use of a non random sample of medically low risk mothers and infants. In addition, the SED women who were excluded from the analysis differed on some characteristics from the SED women who were included. Furthermore the identification of SED women was limited by the variables measured in the larger mother-infant survey. For example, the low-income cut-off in large Ontario cities for a family of two is $\$ 25,867$ [42] whereas the data did not allow for discrimination between women with family incomes ranging from $\$ 20,000$ to $\$ 40,000$. Finally, the use of health and social services was measured by women's self report, potentially resulting in recall bias and should be confirmed by other methods such as physician and public health chart audits.

\section{Conclusion}

The postpartum period presents a unique window of opportunity for community-based health and social service providers and programs to contribute to the elimination of health disparities experienced by SED women and in turn their children. At government and community agency levels, policy makers must recognize that SED women are a heterogeneous group who are at high risk for experiencing health inequities in the postpartum period. Consequently, resources need to be dedicated, and a spectrum of innovative approaches must be developed to support effective health and social services that focus on both the health of these women and their infants. The findings indicate that public health nurses and family physicians are well situated to assist SED women in accessing needed services in the early postpartum weeks. More research is 
required to further examine what kinds of services SED women need in the early postpartum weeks, and what facilitates and hinders access to these services. Phase II of our mixed methods study takes a qualitative descriptive approach to further investigate SED postpartum women's experiences in the first four weeks at home to understand their health service needs and the spectrum of facilitators and barriers to accessing health services.

\section{Competing interests}

The authors declare that they have no competing interests.

\section{Authors' contributions}

CKL conceived of and designed the study, undertook the statistical analysis, interpretation and drafted the manuscript. WS contributed to the study design, interpretation of the results and critically reviewed the manuscript. DC contributed to the study design, interpretation of results and critically reviewed the manuscript. All authors read and approved the final manuscript.

\section{Acknowledgements}

CKL thanks Dr. Ruta Valaitis, RN, PhD at McMaster University for her valuable input throughout the research study.

\section{References}

I. Browne G, Roberts J, Bryne C, Gafni A, Weir R, Majumdar B: More effective and less expensive community approaches to care of vulnerable populations: lessons from 12 studies in Ontario. CJNR 200I, 33:65-76.

2. Flaskerud JH, Winslow BJ: Conceptualizing vulnerable populations' health-related research. Nurs Res 1998, 47:69-78.

3. O'Campo P, Rojas-Smith L: Welfare reform and women's health: review of the literature and implications for state policy. JPHP 1998, 19:420-446.

4. Moss NE: Gender equity and socioeconomic inequality: a framework for the patterning of women's health. Soc Sci Med 2002, 54:649-661.

5. Fergerson SS, Jamieson DJ, Lindsay M: Diagnosing postpartum depression: can we do better? Am J Obstet Gynecol 2002, 186:899-902.

6. Hobfoll SE, Ritter C, Lavin J, Hulsizer MR, Cameron RP: Depression prevalence and incidence among inner-city pregnant and postpartum women. J Consult Clin Psychol 1995, 63:445-453.

7. Morris-Rush JK, Freda MC, Bernstein PS: Screening for postpartum depression in an inner-city population. Am J Obstet Gynecol 2003, 188:1217-1219.

8. Seguin L, Potvin L, St Denis M, Loiselle J: Socio-environmental factors and postnatal depressive symptomatology: a longitudinal study. Women's Health 1999, 29:57-72.

9. Gavin NI, Gaynes BN, Lohr KN, Meltzer-Brody S, Gartlehner G, Swinton T: Perinatal depression: A systematic review of prevalence and incidence. Obstet Gynecol 2005, 106:107|-1083.

10. O'Hara M, Swain A: Rates and risk of postpartum depression a meta-analysis. Int Rev Psychiatry 1996, 8:37-54.

II. Bodnar LM, Cogswell ME, Scanlon KS: Low income postpartum women are at risk of iron deficiency. I Nutr 2002, 1 32:2298-2302.

12. Copeland D, Harbaugh BL: Differences in parenting stress between married and single first time mothers at six to eight weeks after birth. Issues Compr Pediatr Nurs 2005, 28:139-52.

13. Harrykissoon SD, Rickert VI, Wiemann CM: Prevalence and patterns of intimate partner violence among adolescent mothers during the postpartum period. Arch Pediatr Adolesc Med 2002, I 56:325-330.
14. Bohn DK, Tebben JG, Campbell JC: Influences of income, education, age, and ethnicity on physical abuse before and during pregnancy. JOGNN 2004, 33:56I-57I.

15. Evers S, Doran L, Schellenberg K: Influences on breastfeeding rates in low income communities in Ontario. Can J Public Health 1998, 89:203-207.

16. Gee CB, Rhodes JE: Adolescent mothers' relationship with their children's biological fathers: social support, social strain, and relationship continuity. JFP 2003, 17:370-383.

17. Galbraith AA, Egerter SA, Marchi KS, Chavez G, Braveman PA: Newborn early discharge revisited: Are California newborns receiving recommended postnatal services? Pediatrics 2003 , I I I:364-7|

18. Aved B, Irwin MM, Cumminings LS, Findeisen N: Barriers to prenatal care for low income women. WIM I993, I 58:493-498.

19. York R, Grant C, Tulman L, Rothman RH, Chalk L, Perlman D: The impact of personal problems on accessing prenatal care in low-income urban African American women. J Perinatol 1999, 19:53-60.

20. Mustard CA, Roos NP: The relationship of prenatal care and pregnancy complications to birth weight in Winnipeg, Canada. Am J Public Health 1994, 84: I 450-1457.

21. Sword W: Influences on the use of prenatal care and support services among women of low income. National Academies of Practice Forums 2000, 2:125-133.

22. Eaton AP: Early postpartum discharge: recommendations from a preliminary report to Congress. Pediatrics 200I, 107:400-403.

23. Cheng C, Fowles ER, Walker LO: Postpartum maternal health care in the United States: A critical review. J Pernat Educ 2006, I 5:34-42.

24. WHO: Postpartum care of the mother and newborn: a practical guide. [http://www.who.int/reproductive-health/publications/ msm $98 \quad 3 / \mathrm{msm} 98 \quad 3 \quad$ 2.html].

25. Pistella CY, Synkewecz CA: Community postpartum care needs assessment and systems development for low income families. J Health Soc Policy 1999, I I:53-64.

26. Ontario Maternity Care Expert Panel: Maternity Care in Ontario 2006: Emerging Crisis, Emerging Solutions. [http:// www.ontla.on.ca/library/repository/mon/I5000/2685/6.pdf]

27. Canada Health Act [http://laws.justice.gc.ca/en/C-6/]

28. Postpartum Implementation Guidelines for Healthy Babies Healthy Children Program [http://www.health.gov.on.ca/english/ providers/pub/child/hbabies/postpartum.html]

29. Canadian Perinatal Report 2003 [http://www.phac-aspc.gc.ca/ publicat/cphr-rspc03/pdf/cphr-rspc03 e.pdf]

30. Healthy Babies, Healthy Children Policy Statement on Universal Screening and Assessment for Healthy Child Development Prenatal to School Age [http://www.health.gov.on.cal english/providers/pub/child/hbabies/policy statement.html]

3I. Broadhead WE, Gehlhead SH, Gruy FV, Kaplan BH: The DukeUNC functional support questionnaire. Med Care 1989, 26:709-721.

32. Cox J, Holden J, Sagovsky R: Detection of postnatal depression: Development of the 10-item Edinburgh Postpartum Depression Scale. Br J Psychiatry 1987, I 50:782-786.

33. Browne G, Gafni A, Roberts CL, Goldsmith A, Jamieson E: Approach to the measurement of costs (expenditures) when evaluating health and social programmes Hamilton, ON: The System Linked Research Unit McMaster University; 1995.

34. Browne G, Arpin K, Corey P, Fitch M, Gafni A: Individual correlates of health service utilization and cost of poor adjustment to chronic illness. Med Care 1990, 28:43-58.

35. Baker $\mathrm{D}$, Taylor $\mathrm{H}$ : The relationship between condition specific morbidity, social support and material deprivation in pregnancy and early motherhood. Soc Sci Med 1997, 45: I 325-1336.

36. Katz D, Gagnon A): Evidence of adequacy of postpartum care for immigrant women. MCN 2002, 34:7I-79.

37. Desmeules M, Gold J, Kazanjian A, Manuel D, Payne J, Visandee B, McDermott S, Mao Y: New approaches to immigrant health assessment. Can J Public Health 2004, 95: I22-126.

38. Immigration and Health. Health policy working paper series. Working paper 0I-05 200I [http://www.hc-sc.gc.ca/sr-sr/pubs/ hpr-rpms/wp-dt/200I-0105-immigration/index-eng.php] 
39. Barclay L, Kent D: Recent immigration and the misery of motherhood: a discussion of pertinent issues. Midwifery 1998, I 4:4-9.

40. Ali JS, McDermott S, Gravel RG: Recent research on immigrant health from Statistics Canada's population surveys. Can J Public Health 2004, 95: 19-24.

41. Canadian Pediatric Society and the Society of Obstetricians and Gynecologists of Canada: Early discharge and length of stay for term birth. Joint policy statement. Soc Obstet Gynaecol Can 1996, 18:128I-5

42. Canadian Council on Social Development [http://
[ www.ccsd.ca/factsheets/fs lico05 bt.htm]

\section{Pre-publication history}

The pre-publication history for this paper can be accessed here:

http://www.biomedcentral.com/1472-6963/8/203/pre

pub

Publish with Bio Med Central and every scientist can read your work free of charge

"BioMed Central will be the most significant development for disseminating the results of biomedical research in our lifetime. "

Sir Paul Nurse, Cancer Research UK

Your research papers will be:

- available free of charge to the entire biomedical community

- peer reviewed and published immediately upon acceptance

- cited in PubMed and archived on PubMed Central

- yours - you keep the copyright

Submit your manuscript here:

http://www.biomedcentral.com/info/publishing_adv.asp 